\title{
Responses of water erosion to rainfall extremes and vegetation types in a loess semiarid hilly area, NW China
}

\author{
Wei Wei, ${ }^{1}$ Liding Chen ${ }^{1 *}$, Bojie Fu, ${ }^{1}$ Yihe Lü $^{1}$ and Jie Gong ${ }^{2}$ \\ ${ }^{1}$ State Key Laboratory of Urban and Regional Ecology, Research Center for Eco-environmental Sciences, Chinese Academy of Sciences, Beijing \\ 100085, China \\ ${ }^{2}$ College of Earth and Environmental Sciences, Lanzhou University, Lanzhou, Gansu 730000, China
}

\begin{abstract}
:
Rainfall extremes (RE) become more variable and stochastic in the context of climate change, increasing uncertainties and risks of water erosion in the real world. Vegetation also plays a key role in soil erosion dynamics. Responses of water erosion to $\mathrm{RE}$ and vegetation, however, remain unclear. In this article, on the basis of the data measured on 15 plots (area: $10 \mathrm{~m} \times$ $10 \mathrm{~m}$ and $10 \mathrm{~m} \times 5 \mathrm{~m}$ ) and the definition of World Meteorological Organization (WMO) on rainfall extremes, 158 natural rainfall events from 1986 to 2005 were analysed, and rain depth and maximal 30-min intensity $\left(\mathrm{MI}_{30}\right)$ were used to define RE. Then, water erosion process under RE and five vegetation types (spring wheat, alfalfa, sea buckthorn, Chinese pine, and wheatgrass) were studied in a key loess semiarid hilly area, NW China. The following findings were made: (1) The minimal thresholds of depth and $\mathrm{MI}_{30}$ for defining RE were determined as $40.11 \mathrm{~mm}$ and $0.55 \mathrm{~mm} / \mathrm{min}$, respectively. Among the studied rainfall events, there were four events with both the variables exceeding the thresholds (REI), five events with depths exceeding $40.11 \mathrm{~mm}$ (REII), and four events with $\mathrm{MI}_{30}$ exceeding $0.55 \mathrm{~mm} / \mathrm{min}$ (REIII). Therefore, not only extreme rainstorm, but also events with lower intensities and long durations were considered as RE. Moreover, RE occurred mostly in July and August, with a probability of 46 and 31\%, respectively. (2) Extreme events, especially REI, in general caused severer soil-water loss. Mean extreme runoff and erosion rates were 2.68 and 53.15 times of mean ordinary rates, respectively. The effect of each event on water erosion, however, becomes uncertain as a result of the variations of RE and vegetation. (3) The buffering capacities of vegetation on RE were generally in the order of sea buckthorn $>$ wheatgrass $>$ Chinese pine $>$ alfalfa > spring wheat. In particular, sea buckthorn reduced runoff and erosion effectively after 3-4 years of plantation. Therefore, to fight against water erosion shrubs like sea buckthorn are strongly recommended as pioneer species in such areas. On the contrary, steep cultivation (spring wheat on slopes), however, should be avoided, because of its high sensitivities to RE. Copyright (c) 2009 John Wiley \& Sons, Ltd.
\end{abstract}

KEY WORDS rainfall extremes; vegetation; runoff; soil erosion; loess semiarid hilly area

Received 21 July 2008; Accepted 26 October 2008

\section{INTRODUCTION}

Water erosion in the Chinese loess hilly area is still very severe, challenging the sustainability of social and environmental security in the locality ( $\mathrm{Fu}, 1989$; Kang et al., 2001; Wei et al., 2006a; Chen et al., 2007a). Special meteorological status and intensified human activity, coupled with harsh natural conditions and fragile ecosystems, are considered as the major trigger and driver of water erosion in this semiarid environment (Shi and Shao, 2000; Wang et al., 2006; Xu et al., 2007).

Among these factors, precipitation extremes, in particular, play important roles in inducing severer water erosion in the semiarid ecosystems than in the temperate areas. For example, studies show that the temporal distribution of heavy rainstorms is especially necessary for assessing runoff amount and erosion rate (Klik and

* Correspondence to: Liding Chen, State Key Laboratory of Urban and Regional Ecology, Research Center for Eco-environmental Sciences, Chinese Academy of Sciences, Beijing 100085, China.

E-mail: liding@rcees.ac.cn
Truman, 2003; Apaydin et al., 2006). The severity, frequency, extent, and impact of soil erosion processes are likely to be altered by the high degree of fluctuation and variation of rainfall depth, intensity and frequencies (Gregory et al., 1999; Sivakumar, 2007). The number, timing and magnitude of storms also greatly impact hydrological processes (Weltzin et al., 2003). Soil erosion, landslides, mass movements, and debris flows have been monitored and found to be more severe when large-scale heavy rainstorms occur (Cheng et al., 2002). The annual nutrient loss due to water erosion, under extremely heavy rainfall, exceeds $50 \%$ of the total amount (Gao et al., 2005). Mannaerts and Gabriels (2000) also found that the dominant seasonal concentration of water erosion was limited to a few major storms only.

More notably, the episodes of rainfall extremes (RE) in nature have been monitored to be more capricious, stochastic, and unpredictable during the past several decades (Weltzin et al., 2003). The intensity, frequency, and regimen of extreme precipitation events, which have already increased globally, are predicted to increase 
further (Easterling et al., 2000; IPCC Working Group I, 2001). This variability will probably increase the complexity and uncertainty of water erosion process (Gregory et al., 1999; Zhang and Liu, 2005a). For example, studies found that changeable precipitation is the main factor in runoff and sediment alteration (Guo, et al., 2002; Jake et al., 2003; Chen et al., 2007b). Recently, a new prediction declares that rain erosivity, which is the major driving force of water erosion, will increase $8-35 \%$ on the Chinese Loess Plateau in the next 10 decades (Zhang and Liu, 2005a). Another study also found high levels of seasonal and annual runoff fluctuations in this region during the past several decades, mainly owing to the varied precipitation patterns $(\mathrm{Xu}$ et al., 2007). High degree of variations and occurrences of RE coupled with fragile earth surface can cause severer consequences of soil erosion and land degradation.

The type, cover, structure, and age of vegetation, on the other hand, are another key factor, besides RE, influencing water erosion processes (Cerdà, 1998; Zhou et al., 2006; Pizarro et al., 2006). Studies found that various hydrological responses occur under different vegetation communities (Fu, 1989; Chen et al., 2003; Zhang et al., 2005b; Zhao et al., 2006). Vegetation plays a key role in intercepting rainfall, increasing water infiltration, fixing soil by roots, providing mechanical protection by reducing raindrop energy and 'splash' effects, and trapping sediment (Gyssels and Poesen, 2003; Rey et al., 2004; Bochet et al., 2006). Water erosion will decrease, if adapted vegetation restoration is applied. In particular, proper plant selection and management (mulching and land closure) can increase surface cover and root energy, improve soil property, and therefore reduce soil erosion (Hou et al., 1996; Cheng et al., 2002; Li et al., 2004; Adekalu et al., 2006). Vegetation destruction (steep cultivation and bare zones caused by deforestation,) or improper species use, on the contrary, may deteriorate soil features and induce severe soil loss as well as land degradation on larger scales (Wang et al., 2003; Pimentel et al., 2004; Li et al., 2007). For example, sloping farmlands converted from forests and grasslands in the loess hilly area have suffered from severe erosion, and water and nutrient loss for a long time (Zheng et al., 2004; Zheng, 2006). Decrease or even disappearance of vegetative cover plays negative role in modifying the processes of rainfall interception and overland flow, which affect the dynamics of surface water cycle and deposition of sediment yields (Kang et al., 2001; Pan and Shuangguan, 2006; Rulli and Rosso, 2007).

However, responses of water erosion to RE remain unclear, and this is especially true under different vegetation types. Studying RE and their erosion responses among vegetation types is thus significant for understanding the comprehensive mechanisms and dynamics of hydrological and erosion processes. Furthermore, consecutive measurements from plot scales for long periods have been confirmed to be of crucial importance for reliable water erosion analysis and prediction on larger scales (Zhang et al., 1996; Licznar and Nearing, 2003). In this study, 158 natural rainfall events producing runoff were used for RE selection. These data sets were based on field measurement and collection extending from 1986 to 2005 (data in 2000 and 2001 missing). The main purpose of this article is to highlight and discuss the responses of water erosion processes to RE and vegetation types in a key loess semiarid hilly area, NW China. Three specific sub-objectives are expected to be achieved: (1) to study the role of RE on water erosion processes; (2) to analyse the buffering capacities of different vegetation types on extreme rates of runoff and erosion; (3) to discuss the combined effect of RE and vegetation types on water erosion processes.

\section{MATERIALS AND METHODS}

\section{Study area}

The study area and experimental plots are located at the field station (Figure 1) of Dingxi Soil and Water Conservation Institute ( $1895 \mathrm{~m}$ a.s.1., $\left.35^{\circ} 33^{\prime} \mathrm{N}, 104^{\circ} 35^{\prime} \mathrm{E}\right)$ in Anjiagou catchment, a typical loess hilly area in Gansu, NW China. This region is dominated by a semiarid continental temperate climate, with two distinct seasons, cold-dry winters and warm-wet summers (Xu et al., 2007). The mean annual precipitation has been about $426.6 \mathrm{~mm}$ over the past five decades, over $80 \%$ of which has fallen in the rainy season from May to September (Wang et al., 2003), with an annual variability of $26 \%$. The maximum and minimum precipitations have been $721.8 \mathrm{~mm}$, in 1967 and $245.7 \mathrm{~mm}$, in 1982 (Huang et al., 2005a). However, the potential annual evaporation can reach $1510 \mathrm{~mm}$. The mean monthly temperature ranges from -7.6 to $27.5^{\circ} \mathrm{C}$, with an average annual temperature of $6 \cdot 3{ }^{\circ} \mathrm{C}$. Annually, about 141 days are frost-free.

Local soil is developed from the wind-accumulated loess parent material, which is about 40-60 $\mathrm{m}$ deep. The dominant soil is calcic Cambisol (FAO-UNESCO, 1974) with clay content of $33 \cdot 12-42 \cdot 17 \%$, organic matter of $3.7-13.4 \mathrm{~g} / \mathrm{kg}$, and soil buck density of $1.09-1.36 \mathrm{~g} / \mathrm{cm}^{3}$ within 2-m depth. Meanwhile, the topography in the study area is fragmentized and complex (Table I), with a mean slope of $14 \cdot 3^{\circ}$ and a gully density of $3 \cdot 14 \mathrm{~km} / \mathrm{km}^{2}$. This type of soil and landform is easy to suffer from serious water erosion ( Fu and Gulinck, 1994; Wei et al., 2006 b).

After hundreds of years of cultivation and other strong human disturbances, most of the natural vegetation in this area has been converted into farmland, causing loss of ground cover protection. The majority of the remainder consists of natural secondary grass species [wheatgrass (Agropyron cristatum L. Gaertn), needle-grass (Stipa capillata Linn.), etc.] and planted vegetation types such as sea buckthorn (Hippophae rhamnoides L.), pea tree (Caragana Korshinskii Kom), poplar (Populus SPP), Chinese arborvitae (Platycladus orientalis L.), Chinese pine (Pinus tabuliformis Carr), and apricot (Prunus armeniaca L.). The main crop species are spring wheat (Triticum aestivum L. cv Leguan), alfalfa (Medicago 

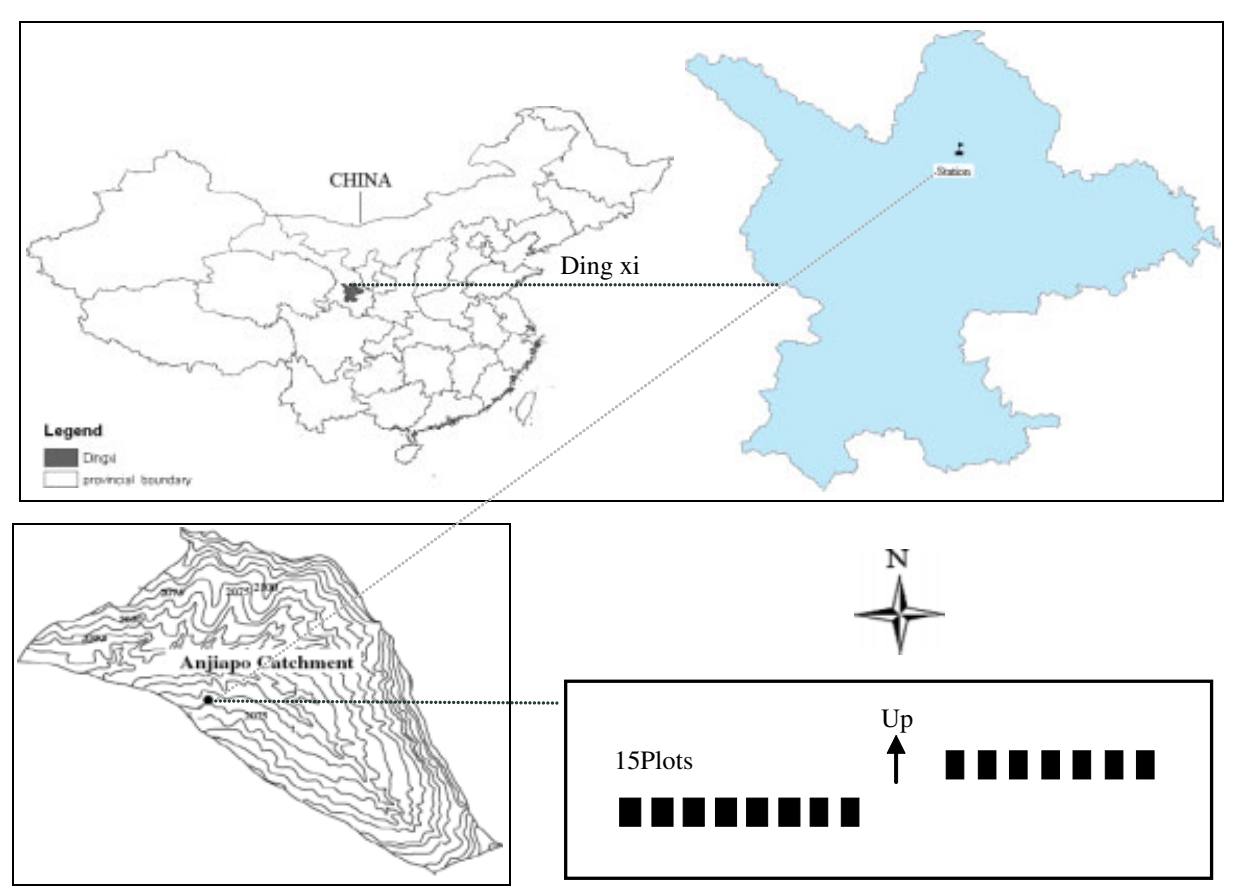

Figure 1. Location of the study area and experimental design

Table I. Topography and gradient features of the study area

\begin{tabular}{|c|c|c|c|c|c|c|c|c|c|c|}
\hline \multirow[t]{2}{*}{ Index } & \multicolumn{6}{|c|}{ Slope gradient } & \multicolumn{4}{|c|}{ Landform } \\
\hline & $<5^{\circ}$ & $5^{\circ}-10^{\circ}$ & $10^{\circ}-15^{\circ}$ & $15^{\circ}-20^{\circ}$ & $20^{\circ}-25^{\circ}$ & $>25^{\circ}$ & Hilltop & Hill slope & Terrace & Gully slope \\
\hline Ratio (\%) & $11 \cdot 7$ & $14 \cdot 1$ & $38 \cdot 9$ & $15 \cdot 1$ & $9 \cdot 3$ & $11 \cdot 2$ & $0 \cdot 9$ & $74 \cdot 6$ & $10 \cdot 8$ & $13 \cdot 7$ \\
\hline
\end{tabular}

sativa L.), potatoes (Solanum tuberosum L.), and maize (Zea mays L.). Because of severe drought and poor soil conditions in situ, most of the artificial plants can not grow well and the productivity remains relatively low.

\section{Experimental manipulation}

In 1986,15 plots were collocated on a north-facing hill-slope, about $100 \mathrm{~m}$ from the meteorological station of Dingxi Soil and Water Conservation Institute. Before constructing the plots, former cultivated rain-fed crops, such as wheat, potatoes, beans, and millet in this area were cleared off. To reduce the effects of position and topography, all the runoff plots were established on the same slope. They were oriented parallel to the slope and adjacent to one another.

The following five vegetation types with three replications have been investigated on the 15 experimental plots (slope degree: $10^{\circ}, 15$ and $20^{\circ}$ ), which were installed in the same year (1986): (1) Spring wheat (T. aestivum L. cv Leguan): field management was similar to that used by local farmers, and the seeds of spring wheat were sown in April each year and harvested manually in late July or early August. Because of bad climate and severe drought, spring wheat remained low in productivity during the periods of measurement. (2) Alfalfa ( $M$. sativa L.): the seeds were sown by drilling or broadcasting in April, 1986 and harvested in late July of the same year. Alfalfa was replanted annually from 1993 to 1999, because of low productivity. (3) Sea buckthorn $(H$. rhamnoides L.): saplings were planted at $1.0 \mathrm{~m}$ by $1.0 \mathrm{~m}$ spacing in March, 1986. Litter remained on the plots without clearance. A few artificial disturbances, due to high density and prickly branches, existed in this plant community. (4) Chinese pine ( $P$. tabulaeformis Carr.): Chinese pine saplings were planted in $3 \cdot 0-\mathrm{m}$ rows and 1.5-m columns in March 1986, without artificial pruning and irrigation. (5) Wheatgrass (A. cristatum L. Gaertn): This natural species was left to grow without any human disturbance since 1986, when the cropland was abandoned, and wheatgrass has now become the dominant species in the patches. It is well known as a good grass species growing in cold arid regions. Meanwhile, the mean annual coverage rate of each vegetation type from 1986 to 2005 was measured (Figure 2).

Plots used for sea buckthorn and Chinese pine were $10 \mathrm{~m} \times 10 \mathrm{~m}$, while plots used for spring wheat, alfalfa, and wheatgrass were $10 \mathrm{~m} \times 5 \mathrm{~m}$. On each plot, cement ridges (about $30 \mathrm{~cm}$ above ground) were constructed at the borders to isolate plot runoff and sediment yield. A discharge ditch was created at the top of each plot to control runoff and sediment yield from the upper slope. At the base of each plot, a marked H-flume and two volumetric tanks were built at the outlet of each plot for surface runoff and sediment collection. 


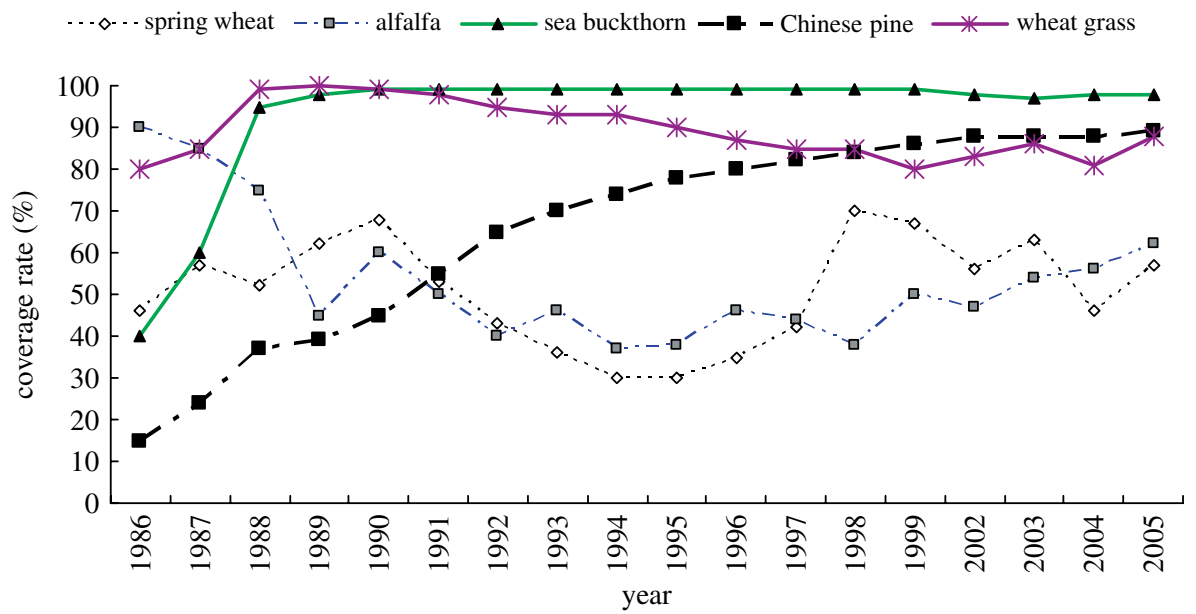

Figure 2. Average annual coverage of vegetation types from 1986 to 2005 (Measurement: The coverage of alfalfa and wheatgrass was estimated in the maximal growth period by 5 quadrates of $1 \mathrm{~m} \times 1 \mathrm{~m}$ within each plot; the coverage of sea buckthorn and pine was measured by means of values of canopy width; the coverage of spring wheat was estimated by the row spacing. The mean coverage rate of three replications was used for each vegetation type.)

\section{Data measurement}

Daily rainfall during the rainy seasons was measured and recorded by a $\mathrm{SM}_{1}$ pluviometer and a $\mathrm{SJ}_{1}$ auto-siphon udometer in the study area. A rainfall event would be separated into two parts and defined as two independent events, if an interval exceeding $6 \mathrm{~h}$ existed during the event. According to the basic information provided by the data logger, several key rainfall variables including depth, duration, average intensity, and maximum 30min intensity $\left(\mathrm{MI}_{30}\right)$ were all calculated and recorded. Runoff volume from each plot in each rainfall event was recorded simultaneously. Sediments from the 15 plots were first sampled using 250-ml bottles, and then deposited, separated from the water, and dried at $105^{\circ} \mathrm{C}$ in a forced air oven to a constant weight. The monitored data were then used to calculate the related hydrological indices representing the degrees of soil erosion and water loss.

\section{Definition of $R E$}

In this study, RE are defined on the basis of the criterion of the World Meteorological Organization (WMO), i.e. when the difference between the specific rainfall variables and corresponding mean values of 30-year measurements exceeds the double variance of each variable, the rainfall events are defined as RE (CCCIN, 2002). Moreover, depth and $\mathrm{MI}_{30}$ are used to determine $\mathrm{RE}$ in this article. The corresponding calculated equation is as follows:

$$
\chi-\varpi>2 \theta
$$

where $\chi$ represents rainfall variable such as depth or intensity, $\varpi$ is the mean value of this variable in 30 years, and $\theta$ is the variance of the related variable.

On the basis of the definition mentioned above, two specific sub-criteria for determining RE were carried out as follows: (1) Rainfall depth exceeds its mean annual value (calculated as $18.87 \mathrm{~mm}$ in this study), and $\mathrm{MI}_{30}$ exceeds the summation of its double variance and annual value. (2) If $\mathrm{MI}_{30}$ can not reach the WMO criterion, rainfall depth must exceed the corresponding criterion. Rainfall events agreeing with one or both of the two criteria will be regarded as an extreme rainfall event.

\section{Clustering and statistical methodology}

In this study, hierarchical clustering method was used to analyse and classify different styles of RE. This method is a fundamental and important tool for statistical analysis, widely used in such diverse scientific fields as psychology, zoology, biology, hydrology, botany, sociology, meteorology, physiognomy, etc. (Yu and $\mathrm{He}$, 2003). It aims to group objects on the basis of their similarities, and the number of clusters is obtained by automatic statistical analysis (Hong, 2003). Two types of hierarchical clustering methods are included, i.e. $\mathrm{R}$ type and Q type ( $\mathrm{Yu}$ and $\mathrm{He}, 2003$ ). R type clustering is used for variable classification, and $\mathrm{Q}$ type clustering for different cases. In this article, $\mathrm{R}$ type clustering procedure is used.

Meanwhile, to open out more specific features of the defined RE, the descriptive statistical method was used for analyzing three key rainfall variables (i.e. rain depth, duration, and $\mathrm{MI}_{30}$ ) shown in Figure 3 and Table II. Furthermore, in order to calculate and analyse the relationships between RE, runoff, erosion, and vegetation types clearly, two indicators including $\mathrm{REr}$ ( $\mathrm{r}=$ runoff) and REe ( $\mathrm{e}=$ erosion), which respectively represent the ratio of extreme runoff coefficient to the mean runoff coefficient and the ratio of extreme erosion modulus to mean erosion modulus, are established in this study and can be determined by the following two mathematical equations:

$$
R E r=M E R C / M R C=(E S R / E P D) /(S R / P D)
$$

where MERC, MRC, ESR, EPD, SR and PD refer to mean extreme runoff coefficient $(\%)$, mean runoff coefficient $(\%)$, extreme surface runoff, extreme precipitation 


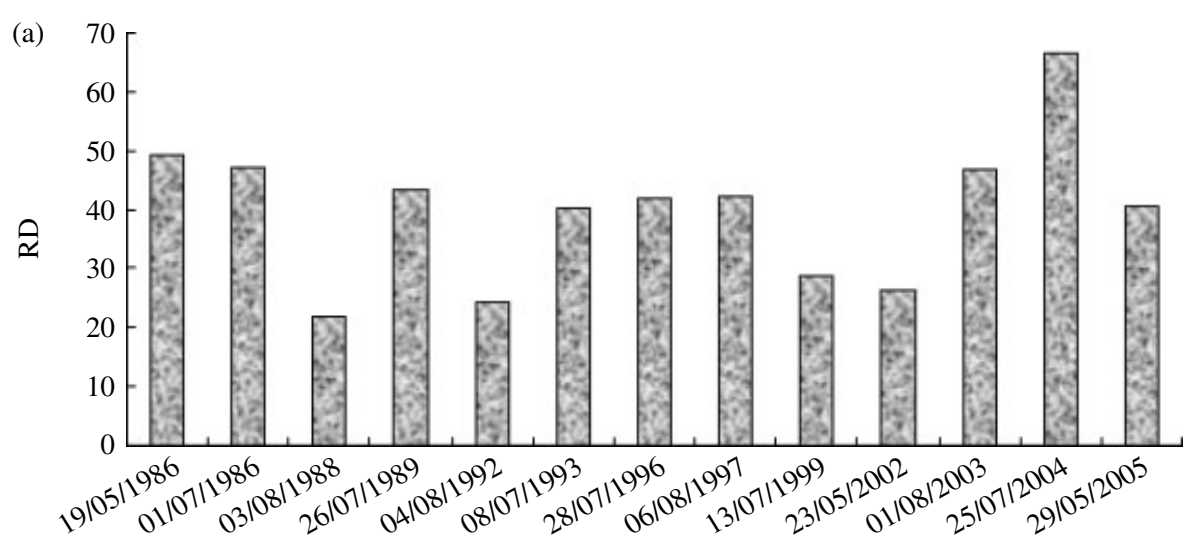

Occurrence time of RE
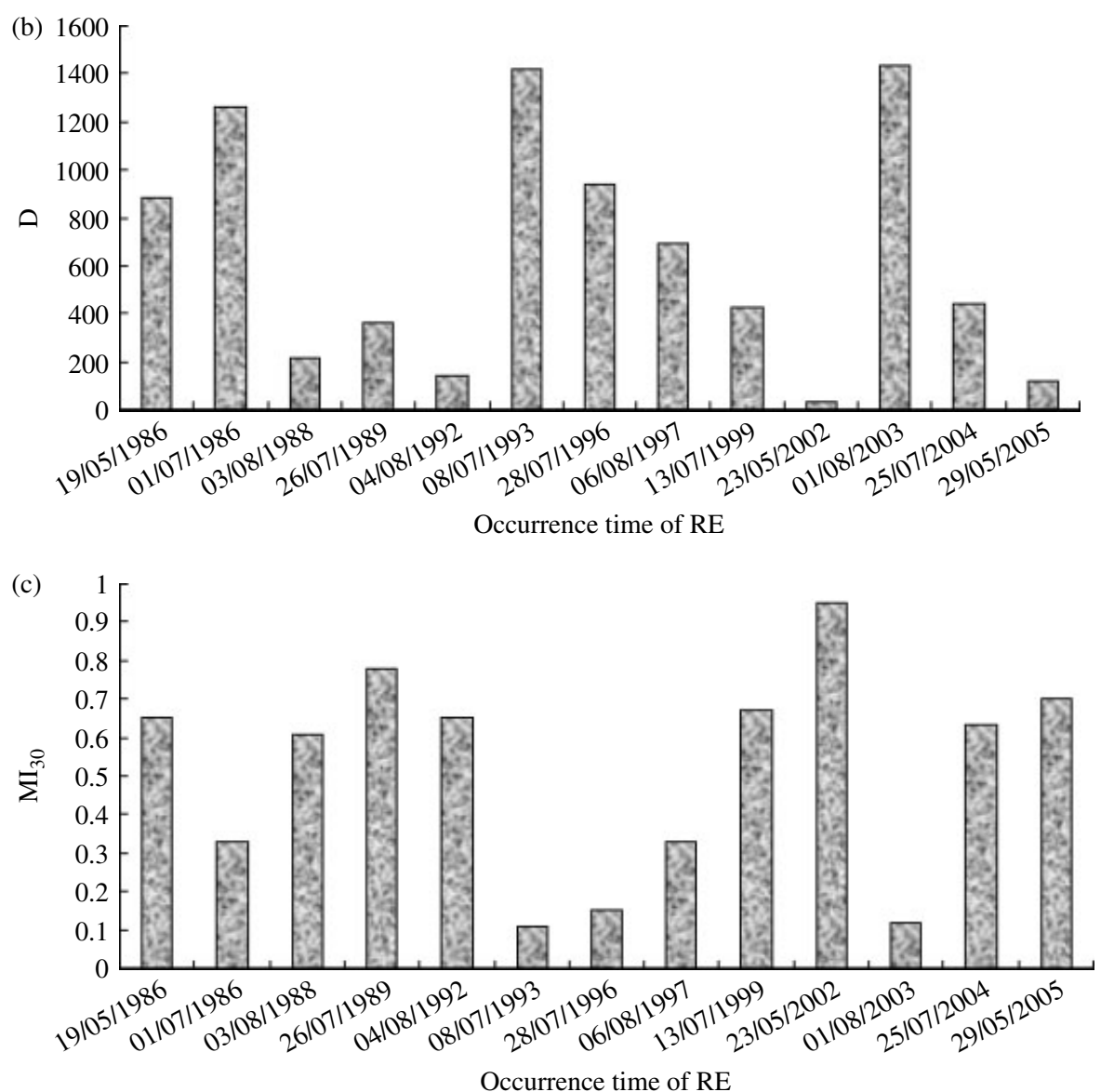

Figure 3. Characteristics of rainfall variables of extreme events. Note: RD, rainfall depth (unit: $\mathrm{mm}$ ); D, duration (unit: min); $\mathrm{MI}_{30}$, maximal intensity in $30 \mathrm{~min}$ (unit: $\mathrm{mm} / \mathrm{min}$ )

Table II. Descriptive Statistics of rainfall variables

\begin{tabular}{|c|c|c|c|c|c|c|c|}
\hline Variable & Range & Minimum & Maximum & Sum & Mean & SD & $\mathrm{CV}$ \\
\hline $\mathrm{RD}(\mathrm{mm})$ & 44.60 & $22 \cdot 00$ & $66 \cdot 60$ & $519 \cdot 00$ & 39.92 & $12 \cdot 22$ & $0 \cdot 31$ \\
\hline $\mathrm{D}(\min )$ & $1407 \cdot 0$ & $22 \cdot 0$ & $1435 \cdot 0$ & $8354 \cdot 0$ & $642 \cdot 6$ & $501 \cdot 9$ & 0.78 \\
\hline $\mathrm{MI}_{30}(\mathrm{~mm} / \mathrm{min})$ & 0.84 & $0 \cdot 11$ & 0.95 & - & 0.51 & $0 \cdot 27$ & 0.53 \\
\hline
\end{tabular}

RD, D, MI30, SD and CV separately refer to rainfall depth, duration and maximal intensity in 30 min, standard deviation and coefficient of variation.

depth, surface runoff and precipitation depth, respectively.

$$
R E e=M E E M / M E M=(E S L / P A) /(S L / P A)
$$

where MEEM, MEM, ESL, SL and PA refer to mean extreme erosion modulus $\left(\mathrm{t} / \mathrm{km}^{2}\right)$, mean erosion modulus $\left(\mathrm{t} / \mathrm{km}^{2}\right)$, soil loss under extreme rainfall events, soil loss under ordinary rainfall events, and area of experimental plot, respectively. 
All the calculations were processed under SPSS 13.0 for windows.

\section{RESULTS}

\section{Defined RE}

According to the consecutive data sets and WMO criterion, the thresholds of depth and $\mathrm{MI}_{30}$ of $\mathrm{RE}$ in the study area are firstly determined, i.e. $40.11 \mathrm{~mm}$ and $0.55 \mathrm{~mm} / \mathrm{min}$, respectively. Meanwhile, the mean depth for the ordinary events is calculated as $18.87 \mathrm{~mm}$. To be an extreme event, each of the two variables should separately exceed the threshold of $40.11 \mathrm{~mm}$ or $0.55 \mathrm{~mm} / \mathrm{min}$. According to this criterion, 13 extreme events were finally screened out from a total of 158 rainfall events from 1986 to 2005 (2000 and 2001 are excluded). All the remaining 145 rainfall events belonged to ordinary events, and are not to be involved in this article.

From the results shown in Figure 3, we can see that extreme events appeared almost every year during the past two decades. More importantly, this kind of events experienced clear variation among different months. During this period, RE occurred six times in July with a probability of $46 \%$, four times in August with a probability of $31 \%$, and three times in May with $24 \%$ probability. No events of RE however, were captured in June and September during the past 20 years. From this point of view, the most important time for paying special attention is July, followed by August, and May.

Meanwhile, it can be seen that the selected rainfall variables experienced high fluctuations among different extreme events during the years from1986 to 2005 (Table II). The rainfall depths of extreme events ranged from 22.00 to $66.60 \mathrm{~mm}$ with a mean value of
$39.92 \mathrm{~mm}$, and this value is far higher than the mean depth $(18.87 \mathrm{~mm})$ of ordinary rainfall events. The duration varied from 22 to 1435 min with a high coefficient of variation of 0.78 . The maximal intensity in $30 \mathrm{~min}$, however, experienced a highest value of $0.95 \mathrm{~mm} / \mathrm{min}$ and a lowest value of $0.11 \mathrm{~mm} / \mathrm{min}$. These quantitative results indicate that not only extremely heavy storms, but also some events with lower intensities and long durations are here considered as RE.

Furthermore, the captured 13 extreme events have been classified into three categories on the basis of their similarities under the procedure of hierarchical clustering method. This is used for analyzing the common features of different types of RE and then discussing their erosive role (Figure 4).

The first category (REI) has such features as depth and $\mathrm{MI}_{30}$, all above the relevant threshold. This kind of events holds a total percentage of $30.77 \%$. The second category (REII) is the aggregation of RE with depth exceeding the related threshold $(40.11 \mathrm{~mm})$, but the value of $\mathrm{MI}_{30}$ does not reach the corresponding standard $(0.55 \mathrm{~mm} / \mathrm{min})$. Herein, five extreme events were captured, holding a total percentage of $38.46 \%$. Although the $\mathrm{MI}_{30}$ of this kind of events is relatively low, it has higher rainfall depths due to longer durations. The third category (REIII) of RE has such features as $\mathrm{MI}_{30}$ exceeding the threshold of $0.55 \mathrm{~mm} / \mathrm{min}$ and the depths in the ranges of $18.87-40.11 \mathrm{~mm}$.

This result also revealed that secondary classifications existed in the last two categories (the lightest broken line shown in Figure 4). Two sub-levels appeared in RE II and RE III. In RE II, for example, two extreme rainfall events belonged to the same sub-category, and the other three extreme events pertain to the other sub-category. The main reason for this can be attributed to the difference of $\mathrm{MI}_{30}$. For category III, however, the $\mathrm{MI}_{30}$ once reached

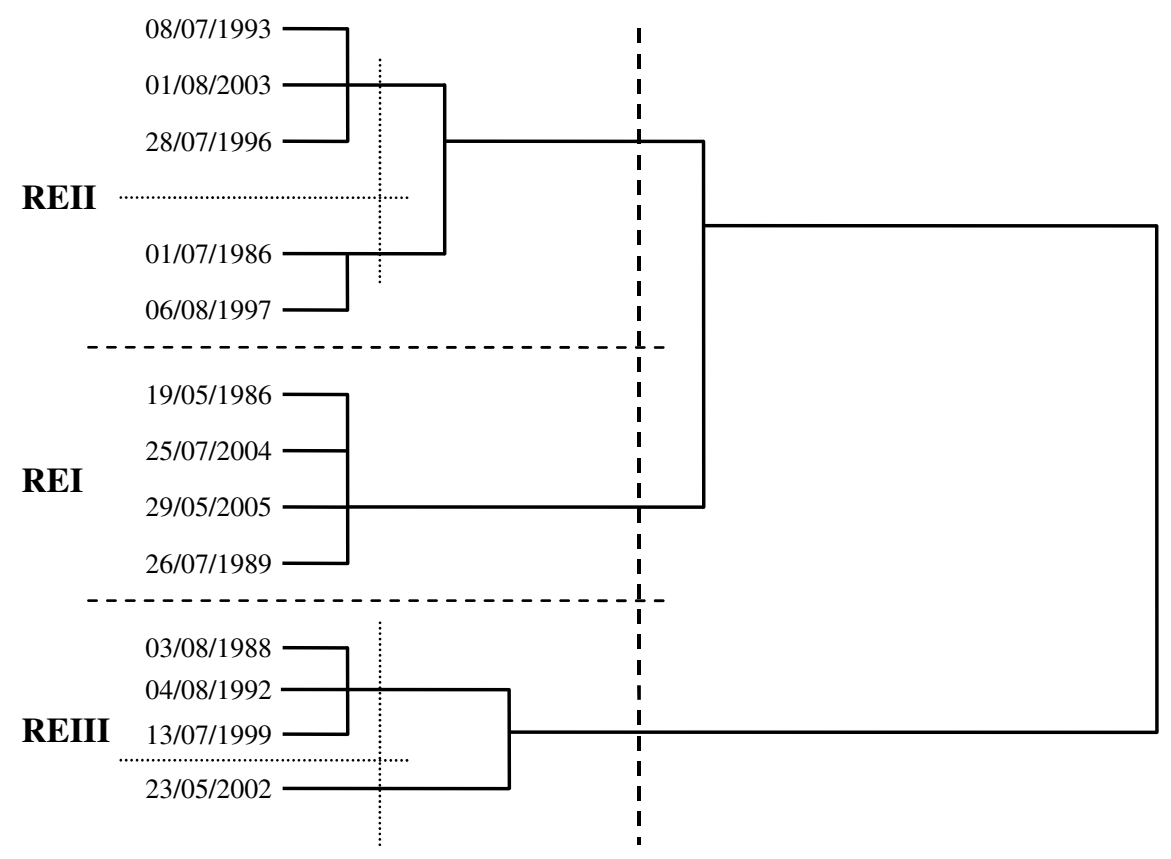

Figure 4. Hierarchical clustering of RE 


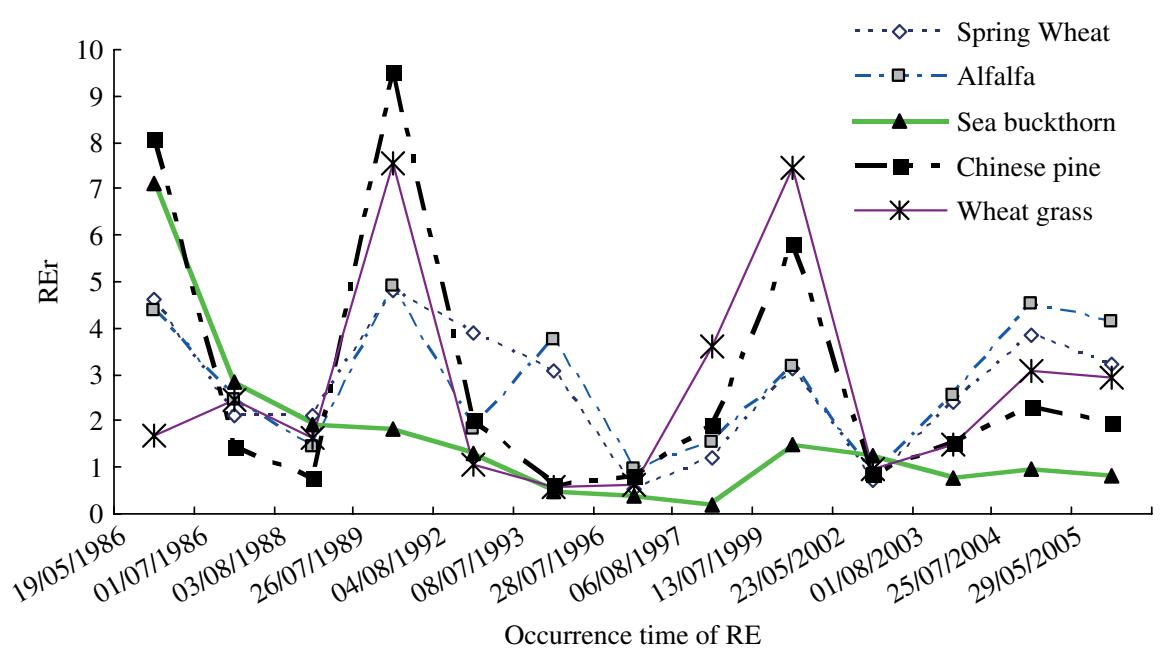

Figure 5. The degrees of water loss under vegetation types and RE

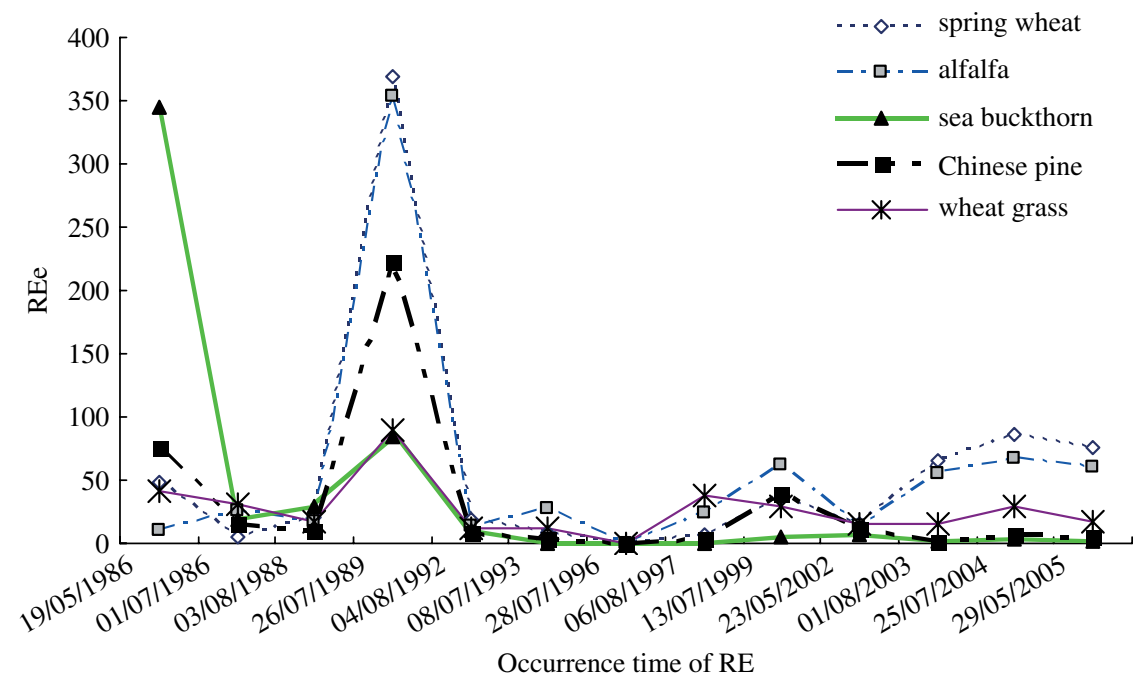

Figure 6. The degrees of soil loss under vegetation types and RE

$0.95 \mathrm{~mm} / \mathrm{min}$, which was the highest maximal intensity of the monitored years, its depth, however, was only $26.5 \mathrm{~mm}$. This event is obviously known from other events in this category.

\section{Runoff under RE and vegetation types}

It is found that the ratios of extreme runoff coefficients to mean runoff coefficients (REr) under different vegetation types and RE are relatively complex and differ from each other (Figure 5). Firstly, in most cases, the runoff coefficients of extreme rainfall events were far higher than those of ordinary rainfall events. For example, the highest value of REr was 9.50 on 26 July 1989 (Figure 5), which appeared for Chinese pine. Secondly, the results show that the ratios of runoff coefficients of different vegetation types under the same extreme event differed greatly. For example, the values of REr of spring wheat and alfalfa on 8 July 1993 were respectively monitored as 4.08 and 4.76 , whereas the related REr values of sea buckthorn, Chinese pine, and wheatgrass were only 0.50 , $0 \cdot 61$, and $0 \cdot 59$. Thirdly, surface runoff for the same vegetation type has different consequences regarding water loss under different extreme rainfall features. For example, the value of REr on 28 July 1996 under sea buckthorn was only $0 \cdot 38$, whereas the value on 1 July 1986 reached $7 \cdot 13$ (Figure 5). Lastly, sea buckthorn was found to have high runoff coefficients under the first two extreme rainfall events (occurred on 19 May and 1 July, both in 1986), and then became very low and relatively stable in the following years.

\section{Erosion under RE and vegetation types}

From Figure 6, we can see that the degree and dynamics of soil loss rate caused by water erosion under the interaction of vegetation types and RE differ from each other. Generally, the ratio of extreme erosion modulus to the mean erosion modulus (REe) is very high under the impact of most of the events. The highest values of REe in the five vegetation types are in the order of spring wheat $(368.53)>$ alfalfa $(353.60)>$ sea buckthorn $(345 \cdot 18)>$ Chinese pine $(222 \cdot 46)>$ wheatgrass $(90 \cdot 45)$. The peak value under each vegetation type however, did not always appear in the same rainfall event. For example, the highest erosion modulus under sea buckthorn was 
observed on 19 May 1986, whereas all the related highest moduli under other four vegetation types appeared on 26 July 1989. Meanwhile, results also showed that the degree of extreme erosion was different among different vegetation types, even under the same extreme rainfall event.

\section{DISCUSSION}

\section{Responses of water erosion process to RE}

According to the results, soil erosion and water loss are severer under RE than under ordinary rainfall events in most cases (Figures 5 and 6). Generally, mean extreme runoff coeffiecient (MERC) and mean extreme erosion modulus (MEEM) are respectively $14.74 \%$ and $1.43 \times$ $10^{5} \mathrm{t} / \mathrm{km}^{2}$, which are 2.68 times and 53.15 times of those under ordinary rainfall events (Table III). The results therefore, re-confirmed the destructive role of RE on water erosion processes reported in other studies (Wang et al., 1996; Gao et al., 2005). Meanwhile, as elaborated previously (Figure 3), the key periods for extreme events to occur are July, August and May, with percentages of $46.15,30.77$ and 23.08 , respectively. Therefore, in order to minimize the destructive role of these kinds of events on surface soil and water, much attention should be paid to the most vital and sensitive periods when soil erosion potentials are highest, i.e. July and August. Furthermore, in order to control severe soil erosion caused by RE more successfully, other countermeasures such as straw mulch, plastic film mulch, and land closure should be taken into account. Such measures are highly valuable in improving soil character and reducing severe water erosion (Li et al., 2004; Huang et al., 2005b; Adekalu et al., 2006).

In this study, extreme rainfall events are grouped into three major categories based on the thresholds of depth and $\mathrm{MI}_{30}$ (Figure 4). Results indicate that the sensitivity of runoff and erosion to different extreme events differs. In general, surface water loss and soil erosion, are more sensitive to the first category of extreme events (REI) than those of other two categories (RE II and RE III), whose

Table III. Mean runoff and soil erosion under extreme events and ordinary events

\begin{tabular}{lcccccc}
\hline Index & $\begin{array}{c}\text { MERC } \\
(\%)\end{array}$ & $\begin{array}{c}\text { MRC } \\
(\%)\end{array}$ & REr & $\begin{array}{c}\text { MEEM } \\
\left(\mathrm{t} / \mathrm{km}^{2} / \mathrm{a}^{1}\right)\end{array}$ & $\begin{array}{c}\text { MEM } \\
\left(\mathrm{t} / \mathrm{km}^{2} / \mathrm{a}^{1}\right)\end{array}$ & REe \\
\hline Value & 14.74 & 5.51 & 2.68 & $1.43 \times 10^{5}$ & 2683 & 53.15 \\
\hline
\end{tabular}

depth and $\mathrm{MI}_{30}$ both exceed the thresholds of $40.11 \mathrm{~mm}$ and $0.55 \mathrm{~mm} / \mathrm{min}$ (Figures 3 and 4 ). For example, the values of REr and REe under rainfall events which occurred on 26 July 1989 are higher than those under the majority of other extreme events, although some variances may appear among different vegetation types. Therefore, from the point of view of rainfall features, RE with high intensity and large amount play a vital role in causing severe soil erosion and water loss in most cases. REII, which is the aggregation of extreme rainfall events with long duration but low intensity, also causes high sensitivity and variation regarding water erosion rates. This important finding indicates that extreme runoff and erosion are not always caused by heavy rainstorms with strong intensities only. Events with long durations but relatively low intensities also play important roles in inducing severe water erosion. This result highlights the characteristics of RE in the key loess semiarid hilly area, mainly because previous studies only considered rainstorms with extremely strong intensities as extreme events (Wang et al., 1984; Wang et al., 1996; Gao et al., 2005). The effect of RE III on runoff and soil erosion, moreover, is also significant, although it has shorter duration and lower depth than the other two RE types. The frequency, intensity and duration of extreme events, which are more consequential to water erosion than the mean values, are stressed in this study. Moreover, according to our results, the specific amount and degree of runoff and erosion under these three extreme rainfall categories are complicated, and it is mainly because the factors which influence water erosion rates and risks are too complex to predict in the real world (Fu, 1989; $\mathrm{He}$ et al., 2004; Wang et al., 2006; Chen et al., 2007b).

\section{Responses of extreme water erosion to vegetation types}

In this study, the extreme rates of runoff and soil loss in the five vegetation types mentioned have been investigated (Table IV). Results show that the types and ages of vegetation play a key role in controlling extreme hydraulic destruction, and this conclusion is very similar to those in other studies (Rey et al., 2004; Bochet et al., 2006). Herein, to understand their specific responses to $\mathrm{RE}$, the five xeric vegetations and their effects on water erosion are separately addressed in detail.

The first one is Chinese pine ( $P$. tabuliformis Carr.). This plant is a traditional pine species in China. Its ability for holding soil water and preventing surface runoff, however, remains controversial. For example, the

Table IV. Extreme runoff and erosion features in each vegetation type

\begin{tabular}{lccccc}
\hline Index & Spring wheat & Alfalfa & Sea buckthorn & Chinese pine & Wheatgrass \\
\hline MERC $(\%)$ & 23.02 & 19.98 & 4.31 & $15 \cdot 83$ & 10.56 \\
MRC $(\%)$ & 8.40 & $7 \cdot 16$ & $2 \cdot 61$ & 5.46 & 3.91 \\
MERC/MRC & 2.74 & 2.79 & 1.65 & $2 \cdot 90$ & 2.70 \\
MEEM $\left(\mathrm{t} / \mathrm{km}^{2} / \mathrm{a}^{1}\right)$ & $4.87 \times 10^{5}$ & $1.87 \times 10^{5}$ & $1.86 \times 10^{3}$ & $2.32 \times 10^{4}$ & $1.39 \times 10^{4}$ \\
MEM $\left(\mathrm{t} / \mathrm{km}^{2} / \mathrm{a}^{1}\right)$ & 8612 & 3321 & 135 & 600 & 427 \\
MEEM/MEM & 56.55 & $56 \cdot 31$ & 13.78 & 38.67 & $32 \cdot 55$ \\
\hline
\end{tabular}


Table V. Features of surface cover and soil hydrological indexes

\begin{tabular}{lccccc}
\hline Index & Spring wheat & Alfalfa & Sea buckthorn & Chinese pine & Wheatgrass \\
\hline MCC $(\%)$ & 48 & 54 & 92 & 74 & 90 \\
SBD $\left(\mathrm{g} / \mathrm{cm}^{3}\right)$ & 1.23 & 1.21 & 1.17 & 1.26 & 1.20 \\
WHC $\%)$ & 14.3 & - & 14.8 & 13.4 & 14.6 \\
LD (mm) & 1.23 & 1.65 & 1.96 & 1.32 & 20 \\
SOM $(\%)$ & & & & 30 & 1.88 \\
\hline
\end{tabular}

MCC, mean canopy cover; SBD, soil buck density, WHC, water holding capacity; LD, litter depth; SOM, soil organic matter.

ratio of MERC and MRC (REr) under Chinese pine is the highest according to our research (Table IV). This implies that it was more sensitive to extreme runoff than the other four vegetation types. Two major reasons are possibly responsible for this phenomenon. First, it could be the long term effects of growing Chinese pine on the physicochemical characteristics of the surface soil. Huang et al. (2005b) found that the surface soil under Chinese pine gradually hardened with time, which decreased water infiltration and increased surface runoff. Second, more grease was observed in the litter of Chinese pine than in other plant litters, which eventually decreased the water holding capacity of the litter and created more surface runoff (Liu et al., 2002).

Alfalfa (M. sativa L.), an excellent fodder for livestock, is planted in large scale in the loess area of China. In this study however, alfalfa was found very sensitive to RE, sometimes even more than spring wheat (Table III). There may be three major reasons for this. First, it was reported that the survival and growth of alfalfa are at the cost of soil water exhaustion (Li et al., 2007), which deteriorates the soil status in situ and thus increases soil erosion, especially under extreme rainfall conditions (Wang et al., 2003). For example, a study in a similar semiarid area found that 11001 of water are required to produce $1 \mathrm{~kg}$ biomass of alfalfa (Pimentel et al., 2004). Second, alfalfa always grows from July to late August. This time happens to be the sensitive season for soil and water loss, mostly because of high rainstorm frequencies and extreme events. Because of its high quality as forage for animal use, local farmers reap alfalfa, disturb the soil, and finally seriously decrease or even uncover the surface layer. In this situation, the risk of runoff and soil erosion dominated by heavy and frequent downpours sharply increases. Thirdly, we found that alfalfa grows well in flat areas (terrace, dam-land, etc.) where soil is fertile and humid, while it grows poorly in sloping areas because of water and nutrient shortages (Unpublished material). Because of these limitations, large-scale plantation of alfalfa with the major purpose of soil and water conservation should be carefully reexamined (Li et al., 2007), and detailed measures and approaches such as land selection for alfalfa growth should also be of concern.

Sea buckthorn (H. rhamnoides L.), famous for its high drought resistance and as an excellent drug rawmaterial, is the most powerful species at fighting against extreme hydrological events among the five types of vegetation (Table IV). The possible reasons are as follows. First, sea buckthorn grows well and has a higher canopy density and coverage, especially after 3-4 years succession (Figure 2, Table IV). Effective vegetative coverage however, is proved to have a markedly negative correlation with erosion rates (Hou et al., 1996; Pizarro et al., 2006). Second, soil under sea buckthorn is more improved than that under the other vegetation types. After about 20 years of succession, the soil buck density of sea buckthorn becomes the lowest of the five vegetation types, at only $1.17 \mathrm{~g} / \mathrm{cm}^{3}$ (Table IV). Its water holding capacity and organic matter content in the soil surface are also higher than those of others. Higher water holding capacity and organic matter content, however, have been found to play key roles in increasing water infiltration and surface roughness (Bissonnais et al., 2005), and they, therefore, increase the runoff threshold and decrease the potential erosion risk. Third, the litter under sea buckthorn was the highest found in a local study in September, 2005 (Table V). Plant litter plays an effective role in weakening raindrop energy, improving soil physiochemical condition, increasing surface roughness and slowing runoff velocities (Hou et al., 1996; Neave and Rayburg, 2007). Meanwhile, thick layer of plant litter may improve soil organic matter (SOM), and SOM may improve water infiltration rate by as much as $150 \%$, thus decreasing runoff amount and velocity (Pimentel et al., 2004). Fourth, the effective root network may help to increase slope stability and anti-splash erosion capability (Cheng et al., 2002).

Spring wheat (T. aestivum L. cv Leguan) was found to play the poorest role in reducing water erosion rates amongst the five vegetation types (Table IV; Figures 5 and 6). The reasons could be attributed to several aspects such as poor density and coverage, bad soil properties, and strong human disturbance (Li et al., 2004; Huang et al., 2005b). For example, low density and poor coverage of spring wheat play ineffectual role in intercepting rainfall and reducing raindrop energy (Robichaud et al., 2006). Meanwhile, as one of the major crop species in this area, the effect of spring wheat on runoff and soil erosion is different from that of the other vegetation types. For instance, the roots of spring wheat are proved to be less powerful in protecting and fixing soil than those of grasses, shrubs or arbors (Zheng et al., 2004). Furthermore, our study indicates that spring wheat is harvested in late July or early August each year, leaving 
the soil to be bare until the next year. This will certainly increase the risks and rates of water erosion. All these factors contribute a lot to the different roles of spring wheat and other four vegetation types in reducing water erosion rates.

Wheatgrass (A. cristatum L. Gaertn), an excellent native grass in fighting against drought and cold weather, always grows well on abandoned farmlands in the loess plateau. Studies indicate that wheatgrass has a powerful ability on controlling extreme water erosion rates, weaker than that of sea buckthorn but higher than those of the other three vegetation types (Table III). Two major factors possibly account for this. One, soil conditions such as soil buck density (SBD), SOM, and water holding capacity (WHC) are all improved after nearly 20 years of succession (Table V). However, lower SBD, and higher SOM and WHC are proved to reduce runoff and soil loss effectively, even under extreme rainfall events (Adekalu et al., 2006). Second, the canopy coverage of wheatgrass however, was lower than that of sea buckthorn but higher than those of the other three vegetation types, according to field investigation (Figure 2). Other studies also drew similar conclusions. For example, because of poor rainfall interception and redistribution, grass communities like wheatgrass were found to play less effective roles in controlling soil erosion in the steep slopes than dense shrubs (Zhang et al., 2005b; Zhao et al., 2006).

\section{Responses of water erosion to the interaction of vegetation types and $R E$}

Results indicate that processes of surface water flow and sediment transportation become complicated and dubious under the co-functions of RE and vegetation types (Figures 5 and 6). The following hypothesis could be proposed to explain our results. First, the features and time-series of RE play key roles in the specific dynamics of water erosion (Figure 3 and Table II). Rainfall variables, which influence the regimes and dynamics of runoff and erosion, are considerably complicated and instantaneous (Gregory et al., 1999; Cheng et al., 2002; Weltzin et al., 2003; Apaydin et al., 2006; Sivakumar, 2007). Second, the effects of vegetation types and growing conditions on soil erosion are also indicated. In general, our study highly emphasizes the combined roles of hydrological and erosional processes under vegetation types and RE. On the one hand, vegetation conditions such as coverage and density change highly with different vegetation ages (Figure 2), which eventually alter the regimes of surface water loss and soil erosion over space and time (Cerdà., 1998; Xu, 2006). This has also been confirmed by other studies. For example, Li et al. (2006) found that the improvement of vegetation coverage rate at landslide reached $89.69 \%$ after over 6 years of natural succession. On the other hand, the amounts/depths, intensities and distributions of extreme events also experienced high temporal variations (Table II and Figure 3). The coupled role of these two factors on water erosion thus became non-linear and difficult to determine in many cases. Although the mean values of runoff and erosion under extreme events are generally higher than those under common events, our study also indicates that there is no exact mathematical relationship between a specific extreme event and the consequent extreme hydrological response. Both previous and recent studies have achieved similar results. For example, many studies have confirmed that the largest rainfall events do not necessarily produce the maximum soil erosion and related extreme fluvial discharge (Romero et al., 1999; Nunes et al., 2005; José et al., 2007). Because of this, the relation between erosion process and extreme rainfall in the semiarid Mediterranean region is still hard to assess and uncover (Michael et al., 2005; José et al., 2007).

Meanwhile, our results also indicate that the stages of vegetation development play a key role in controlling and altering water erosion processes, resulting in the hydrological response becoming increasingly more insensitive to RE. For example, sea buckthorn was very sensitive to $\mathrm{RE}$ at initial stages after plantation, exhibiting the highest REr for extreme events that occurred on 19 May 1986, 1 July 1986 and 3 August 1988, and also REe on 19 May 1986 (Figures 5 and 6). After three to four successive years, however, water erosion in sea buckthorn became less sensitive to RE, and thus little soil and water loss was created. Therefore, to fight against severe water erosion caused by RE in larger scales, more special attention should be paid not only to the spatial re-adjustment of vegetation types, but also to the different stages of gowth of the vegetation.

\section{CONCLUSIONS}

In this study, on the basis of field measured hydrological data and the definition of WMO on extreme events, two rainfall variables including depth and $\mathrm{MI}_{30}$ were used to determine and classify RE. The following results were obtained: First, the thresholds of depth and $\mathrm{MI}_{30}$ for RE are separately calculated as $40.11 \mathrm{~mm}$ and $0.55 \mathrm{~mm} / \mathrm{min}$, with the mean depth of ordinary events being $18.87 \mathrm{~mm}$. Results indicate that not only extremely heavy rainstorms, but also some rainfall events with lower intensities and long durations should be considered as RE. Secondly, extreme events cause severer hydrological destruction in most cases, especially for the events whose depth and $\mathrm{MI}_{30}$ all above the thresholds (REI). The specific erosion consequence, however, becomes complex and uncertain due to the differences of rainfall variables, timing, frequency, vegetation types, etc. Thirdly, as a result of the influence of vegetation types and their ages, responses of water erosion to different extreme events differ. The buffering capacity of the five vegetation types on RE was generally in the order of sea buckthorn $>$ wheatgrass $>$ Chinese pine $>$ alfalfa $>$ spring wheat. Perennial plants such as sea buckthorn were monitored to be sensitive to RE in the first 3-4 years after plantation. However, with the vegetative succession going on, the role of sea buckthorn in reducing water erosion rates enhanced significantly. 
These findings have important implications for controlling water erosion caused by RE in the semiarid environments. For example, although RE may generally cause severe water erosion and soil loss, the highest erosion rate are not necessarily caused by the severest extreme event. Therfore, to fight against water erosion more effectively special attention should be paid to the characteristics of RE and vegetation types. Other measures such as mulching and land closure are encouraged for protecting the surface soil from severe erosion. Meanwhile, land use readjustment and vegetation restoration are strongly needed. The shrub, sea buckthorn was intensely recommended to be pioneer species because of its high quality in fighting extreme hydrological events, especially after 3-4 years of plantation. Slope cultivation (spring wheat planted on deep slopes), however, should be avoided in most possible cases, because of its higher sensitivity to extreme rainfall events.

\section{ACKNOWLEDGEMENTS}

We thank the Dingxi Institute of Soil and Water Conservation in Gansu province, for their assistance on field work. Sincere thanks and appreciations are also transferred to Ms Vicky and the two anonymous reviewers, for their valuable and constructive comments. This research was supported by the National Basic Research Program of China (2009CB421104), Knowledge Innovation Project of the Chinese Academy of Sciences (kzcx2-yw421), the National Natural Science Foundation of China (40801041), and the National Advanced Project of the Eleventh Five-year Plan of China (2006BAC10B05).

\section{REFERENCES}

Adekalu KQ, Okunada DA, Osunbitan JA. 2006. Compaction and mulching effect on soil loss and runoff from two southwestern Nigeria agricultural soils. Geoderma 137: 226-230.

Apaydin H, Erpul G, Bayramin I, Gabriels D. 2006. Evaluation of indices for characterizing the distribution and concentration of precipitation: A case for the region of Southeastern Anatolia Project, Turkey. Journal of Hydrology 328: 726-732.

Bissonnais YL, Cerdan O, Lecomte V, Benkhadra H, Souchère V, Martin P. 2005. Variability of soil surface characteristics influencing runoff and inter-rill erosion. Catena 62: 111-124.

Bochet E, Poesen J, Rubio JL. 2006. Runoff and soil loss under individual plants of a semiarid Mediterranean shrubland: influence of plant morphology and rainfall intensity. Earth Surface Processes and Landforms 31: 536-549.

Cerdà A. 1998. The influence of geomorphological position and vegetation cover on the erosional and hydrological processes on a Mediterranean hillslope. Hydrological Processes 12: 661-671.

Chen H, Guo SL, Xu CY, Singh VP. 2007a. Historical trends of hydroclimatic variables and runoff response to climate variability and their relevance in water resource management in the Hanjiang basin. Journal of Hydrology 344: 171-184.

Chen LD, Messing I, Zhang SR, Fu BJ, Ledin S. 2003. Land use evaluation and scenario analysis towards sustainable planning on the Loess Plateau in China. Catena 54: 303-316.

Chen LD, Wei W, Fu BJ, Lü YH. 2007b. Soil and water conservation on the Loess Plateau in China: Review and Perspective. Progress in Physical Geography 31: 389-403.

CCCIN (China Climate Change Information Network). 2002. Climate change: observation facts and future scenarios. http://www.ccchina.gov. $\mathrm{cn} / \mathrm{cn} /$ NewsInfo.asp?NewsId=3979 (in Chinese).
Cheng JD, Lin LL, Lu HS. 2002. Influences of forests on water flows from headwater watersheds in Taiwan. Forest Ecology and Management 165: 11-28.

Easterling DR, Meehl GA, Parmesan C, Changnon SA, Karl TR, Mearns LO. 2000. Climate extremes: Observations, modeling, and impacts. Science 289: 2068-2074.

FAO-UNESCO. 1974. Soil map of the world (1:5000 000). Food and Agriculture Organization of the United Nations. UNESCO: Paris.

Fu BJ. 1989. Soil erosion and its control in the Loess Plateau of China. Soil Use and Management 5: 76-82.

Fu BJ, Gulinck H. 1994. Land evaluation in an area of severe erosion: the Loess Plateau of China. Land Degradation and Development 5: $33-40$.

Gao C, Zhu J, Zhu J, Hosen Y, Zhou J, Wang D, Wang L, Dou Y. 2005. Effects of extreme rainfall on the export of nutrients from agricultural land. Acta Geographica Sinica 60: 991-997 (In Chinese with English abstract).

Guo SL, Wang JX, Xiong LH, Ying AW. 2002. A macro-scale and semidistributed monthly water balance model to predict climate change impacts in China. Journal of Hydrology 268: 1-15.

Gregory P, Ingram J, Campbell B, Goudriaan J, Hunt T, Landsberg J, Linder S, Stafford-Smith M, Sutherst B, Valentin C. 1999. Managed production systems. In The Terrestrial Biosphere and Global Change. Implications for Natural and Managed Ecosystems. Synthesis Volume. International Geosphere-Biosphere Program Book Series 4, Walker B, Steffen W, Canadell J, Ingram J (eds). Cambridge University Press: Cambridge; 229-270.

Gyssels G, Poesen J. 2003. The importance of plant root characteristics in controlling concentrated flow erosion rates. Earth Surface Processes and Landforms 28: 371-384.

He XB, Tian JL, Tang KL, Sun JZ, John MA. 2004. Bio-climatic imprints on a Holocene loess palaeosol from China. Journal of Asian Earth Sciences 22: 455-464.

Hong N (ed.). 2003. Products and Servicing Solution Teaching Book for SPSS of Windows Statistical. Tsinghua University Press, and Beijing Communication University Press: Beijing; 300-311 (in Chinese with English abstract).

Hou XL, Bai G, Cao Q. 1996. Study on benefits of soil and water conservation of forest and its mechanism in loess hilly region. Research of Soil and Water Conservation 3(2): 98-103 (in Chinese with English Abstract).

Huang YL, Chen LD, Fu BJ, Huang ZL, Gong J. 2005a. The wheat yields and water-use efficiency in the Loess Plateau: straw mulch and irrigation effects. Agricultural Water Management 72: 209-222.

Huang ZL, Fu BJ, Chen LD. 2005b. Differentiation of soil erosion by different slope, land use pattern and variation of precipitation in loess hilly region. Science of Soil and Water Conservation 3(4): 11-18. in Chinese with English abstract).

IPCC (Intergovernmental Panel on Climate Change) Working Group I. 2001. Contribution of working group I to the third assessment report of the IPCC.. In Climate Change 2001: The scientific basis. Cambridge University Press: Cambridge.

Jake FW, Michael EL, Susanne S, David GW, et al. 2003. Assessing the response of terrestrial ecosystems to potential changes in precipitation. Bioscience 53(10): 941-952.

José CG, José LP, de Luis M. 2007. A review of daily soil erosion in Western Mediterranean area. Catena 71: 193-199.

Kang SZ, Zhang L, Song XY, Zhang SH, Liu XZ, Liang YL, Zheng SQ. 2001. Runoff and sediment loss responses to rainfall and land use in two agricultural catchments on the Loess Plateau of China. Hydrological Processes 15(6): 977-988.

Klik A, Truman CC. 2003. What is a typical rainstorm? In: Gabriels D., Cornelis W. (Eds.), Proceedings of the International Symposium, 25 Years of Assessment of Erosion, 22-26 September 2003, Ghent, Belgium; 93-98.

Licznar P, Nearing MA. 2003. Artificial neural networks of soil erosion and runoff prediction at the plot scale. Catena 51: 89-114.

Li FM, Wang J, Xu JZ, Xu HL. 2004. Productivity and soil response to plastic film mulching durations for spring wheat on entisols in the semiarid Loess Plateau of China. Soil \& Tillage Research 78: 9-20.

Li J, Chen B, Li XF, Cheng JM, Hao MD. 2007. Effects of deep soil desiccation on alfalfa grasslands in different rainfall areas of the Loess Plateau of China. Acta Ecologica Sinica 27: 75-89. (In Chinese with English abstract).

Liu GQ, Wang H, Qin DY, Ni WJ. 2002. Hydrological and ecological functions of litter layers for main forest-types in Qinling Mts. of the Yellow River. Journal of Natural Resources 17: 55-61. (in Chinese with English abstract). 
Li WT, Lin CY, Chou WC. 2006. Assessment of vegetation recovery and soil erosion at landslides caused by a catastrophic earthquake: A case study in Central Taiwan. Ecological Modelling 28: 79-89.

Mannaerts CM, Gabriels D. 2000. A probabilistic approach for predicting rainfall soil erosion losses in semiarid areas. Catena 40: 403-420.

Michael A, Schmidt J, Enke W, Deutschländer Th, Malitz G. 2005. Impact of expected increase in precipitation intensities on soil loss-results of comparative model simulations. Catena 61: 155-164.

Neave M, Rayburg S. 2007. A field investigation into the effects of progressive rainfall-induced soil seal and crust development on runoff and erosion rates: The impact of surface cover. Geomorphology 87: 378-390.

Nunes JP, Vieira GN, Seixas J, Gonçalves P, Carvalhais N. 2005. Evaluating the MEFIDIS model for runoff, soil erosion prediction during rainfall events. Catena 61: 210-228.

Pan CZ, Shangguan ZP. 2006. Runoff hydraulic characteristics and sediment generation in sloped grassplots under simulated rainfall conditions. Journal of Hydrology 331: 178-185.

Pimentel D, Berger B, Filiberto D, et al. 2004. Water resources: Agricultural and environmental issues. BioScience 54: 909-918.

Pizarro R, Araya S, Jordán C, Farías C, Flores JP, Bro P. 2006. The effects of changes in vegetative cover on river flows in the Purapel river basin of central Chile. Journal of Hydrology 327: 249-257.

Rey F, Ballais JL, Marre A, Rovéra G. 2004. Rôle de la végétation dans la protection contre l'érosion hydrique de surface [Role of vegetation in protection against surface hydric erosion]. Comptes Rendus Geosciences 336: 991-998.

Robichaud PR, Lillybridge TR, Wagenbrenner JW. 2006. Effects of postfire seeding and fertilizing on hillslope erosion in north-central Washington, USA. Catena 67: 56-67.

Romero MA, Cammeraat LH, Vacca A, Kosmas C. 1999. Soil erosion at three experimental sites in the Mediterranean. Earth Surface Processes and Landforms 24: 1243-1256.

Rulli MC, Rosso R. 2007. Hydrologic response of upland catchments to wildfires. Advances In Water Resources 30: 2072-2086.

Shi H, Shao MA. 2000. Soil and water loss from the Loess Plateau in China. Journal of Arid Environments 45: 9-20 \&.

Sivakumar MVK. 2007. Interactions between climate and desertification. Agricultural and Forest Meteorology 142: 143-155.

Wang L, Shao MA, Wang QJ, Gale WJ. 2006. Historical changes in the environment of the Chinese Loess Plateau. Environmental Science \& Policy 9: 675-684.

Wang MB, Li HJ, Chai BF. 1996. Effect of extreme rainfall on the soil water cycle of forest land. Journal of Soil Erosion and Water Conservation 2(3): 83-86. (In Chinese with English abstract).

Wang WZ. 1984. Study on the relationship between rainfall character and soil loss: criterion of erosive rainfall. Bulletin of Soil and Water Conservation 4(2): 58-62. (in Chinese).
Wang ZY, Wang GQ, Li CZ, Wang FX. 2003. Primary study and implication of vegetation-erosion dynamics. Science in China (Series D) 33(10): 1013-1023.

Wei J, Zhou J, Tian JL, He XB, Tang KL. 2006a. Decoupling soil erosion and human activities on the Chinese Loess Plateau in the $20^{\text {th }}$ century. Catena 68: $10-15$.

Wei W, Chen LD, Fu BJ, Gong J. 2006b. Mechanism of soil and water loss under rainfall and earth surface characteristics in a semiarid loess hilly area. ACTA ECOLOGICA SINICA 26: 3847-3853.

Weltzin JF, Loik ME, Schwinning S, et al. 2003. Assessing the Response of Terrestrial Ecosystems to Potential Changes in Precipitation. Bioscience 53: 941-952.

$\mathrm{Xu}$ JX. 2006. Coupling relationship between precipitation and vegetation and the implications in erosion on the Loess Plateau, China. ACTA GEOGRAPHICA SINICA 61: 57-65. In Chinese with English abstract).

Xu ZX, Li JY, Liu CM. 2007. Long-term trend analysis for major climate variables in the Yellow River basin. Hydrological processes 21: $1935-1948$.

Yu J, He X (eds). 2003. Data Statistical Analysis and Application of SPSS Software. People's Post Press: Beijing; 253-276 (in Chinese).

Zhang XC, Liu WZ. 2005a. Simulating potential response of hydrology, soil erosion, and crop productivity to climate change in Changwu tableland region on the Loess Plateau of China. Agricultural and Forest Meteorology 131: 127-142.

Zhang XC, Nearing MA, Risse LM, Gregaor KC. 1996. Evaluation of WEPP runoff and soil loss predictions using natural runoff plot data. Transaction of the ASAE 39: 855-863.

Zhang XX, Yu XX, Wu SH, Wei TX, Zhang XP. 2005b. Effects of forest vegetation on runoff and sediment production on sloping lands of loess area. Chinese Journal of Applied Ecology 16: 1613-1617. in Chinese with English abstract).

Zhao HB, Liu GB, Cao QY, Wu RJ. 2006. Influence of different land use types on soil erosion and nutrient care effect in loess hilly region. Journal of Soil and Water Conservation 20: 20-24. in Chinese with English abstract).

Zheng FL. 2006. Effect of Vegetation Changes on Soil Erosion on the Loess Plateau. Pedosphere 16: 420-427.

Zheng FL, Merrill SD, Huang CH, Tanaka DL, Darboux F, Liebig MA Halvorson AD. 2004. Runoff, Soil Erosion and Erodibility of Conservation Reserve Program Land under Crop and Hay Production. Soil Science Society of America Journal 68: 1332-1341.

Zhou ZC, Shangguan ZP, Zhao D. 2006. Modeling vegetation coverage and soil erosion in the Loess Plateau area of China. Ecological modelling 198: 263-268. 